\title{
Overexpression of hypoxia-inducible factor prolyl hydoxylase-2 attenuates hypoxia-induced vascular endothelial growth factor expression in luteal cells
}

\author{
ZHENGHONG ZHANG ${ }^{1,2}$, XUNSHENG PANG $^{1,3}$, ZONGHAO TANG $^{1}$, \\ DINGZHONG YIN $^{1,3}$ and ZHENGCHAO WANG ${ }^{1}$
}

\author{
${ }^{1}$ Provincial Key Laboratory for Developmental Biology and Neurobiology, College of Life Science, Fujian Normal \\ University, Fuzhou, Fujian 350007; ${ }^{2}$ Provincial Research Center for Animal Transgenesis and Biopharming, College of \\ Veterinary Medicine, Yangzhou University, Yangzhou, Jiangsu 225009; ${ }^{3}$ Department of Animal Science, \\ Laboratory of Animal Reproduction, College of Animal Science and Technology, Anhui Science \\ and Technology University, Bengbu, Anhui 233100, P.R. China
}

Received August 4, 2014; Accepted April 15, 2015

DOI: $10.3892 / \mathrm{mmr} .2015 .3788$

\begin{abstract}
Vascularendothelial growthfactor(VEGF)-dependent angiogenesis has a crucial role in the corpus luteum formation and their functional maintenances in mammalian ovaries. A previous study by our group reported that activation of hypoxia-inducible factor (HIF)- $1 \alpha$ signaling contributes to the regulation of VEGF expression in the luteal cells (LCs) in response to hypoxia and human chorionic gonadotropin. The present study was designed to test the hypothesis that HIF prolyl-hydroxylases (PHDs) are expressed in LCs and overexpression of PHD2 attenuates the expression of VEGF induced by hypoxia in LCs. PHD2-overexpressing plasmid was transfected into LC2 cells, and successful plasmid transfection and expression was confirmed by reverse transcription quantitative polymerase chain reaction and western blot analysis. In addition, the present study investigated changes of HIF-1 $\alpha$ and VEGF expression after incubation under hypoxic conditions and PHD2 transfection. PHD2 expression was significantly higher expressed than the other two PHD isoforms, indicating its major role in LCs. Moreover, a significant increase of VEGF mRNA expression was identified after incubation under hypoxic conditions, which was, however, attenuated by PHD2 overexpression in LCs. Further analysis also indicated that this hypoxia-induced increase in the mRNA expression of VEGF was consistent with increases in the protein levels of HIF-1 $\alpha$, which is regulated by
\end{abstract}

Correspondence to: Dr Zhengchao Wang, Provincial Key Laboratory for Developmental Biology and Neurobiology, College of Life Science, Fujian Normal University, 8 Shangsan Road, Fuzhou, Fujian 350007, P.R. China

E-mail: zcwang@fjnu.edu.cn

Key words: hypoxia-inducible factor-1 alpha, hypoxia inducible factor prolyl-hydroxylase, vascular endothelial growth factor, hypoxia, luteal cell
PHD-mediated degradation. In conclusion, the results of the present study indicated that PHD2 is the main PHD expressed in LCs and hypoxia-induced VEGF expression can be attenuated by PHD2 overexpression through HIF-1 $\alpha$-mediated mechanisms in LCs. This PHD2-mediated transcriptional activation may be one of the mechanisms regulating VEGF expression in LCs during mammalian corpus luteum development.

\section{Introduction}

Vascular endothelial growth factor (VEGF) has a fundamental role in the physiological angiogenesis and the vascularization of the follicular luteinizing granulosa layer during corpus luteum (CL) formation (1-4). Inhibition of VEGF in vivo during the luteal phase prevents luteal angiogenesis and subsequent progesterone secretion (5-8), while an excess VEGF generation during the vascularization of multiple follicles is also thought to cause ovarian hyperstimulation syndrome (OHSS) (9-11). Therefore, the molecular regulation of luteal VEGF expression becomes more and more important.

A previous study by our group reported that hypoxia-inducible factor (HIF)-1 $\alpha$ contributes to the transcriptional regulation of VEGF in luteal cells (LCs) (12). HIF-1, a helix-loop-helix transcriptional factor, which consists of HIF- $1 \alpha$ and HIF-1 $\beta$, has been cloned and characterized as a transcriptional activator of numerous oxygen-sensitive genes, including erythropoietin $(13,14)$, heme oxygenases $(15,16)$, transferrin $(16)$, and several glycolytic enzymes (13-17). It has been indicated that HIF-1 $\alpha$ is inducible by a decrease in tissue or cellular $\mathrm{O}_{2}(15,16)$. HIF-1 $\beta$ is not inducible, but it can bind to HIF-1 $\alpha$ to form a dimer to activate the transcription of numerous genes containing cis hypoxia-response element (HRE) in their promoter or enhancer regions $(15,16)$. Previously, a chromatin immunoprecipitation (ChIP) assay indicated that estrogen can simultaneously induce the recruitment of HIF-1 $\alpha$ as well as $-\beta$ to the upstream HRE and ER $\alpha$ to the proximal GC-rich region of the VEGF promoter, which mediates transcriptional activation of the murine VEGF gene (18-20). 
It has been demonstrated that PHDs are the major enzymes to promote the degradation of HIF-1 $\alpha$ (21-23). PHD catalyzes site-specific proline hydroxylation of HIF-1 $\alpha$, and PHD is recognized and targeted for degradation by the ubiquitin-proteasome pathway. Three isoforms of PHD, including PHD1, -2, and -3 , have been identified (21-24). Previous studies by our group have indicated that PHD2 participates in functional regulation, including sensing high-salt intake and maintaining normal blood pressure, through regulating HIF- $\alpha$ levels (25) and also has a role in angiogenesis (26).

Given the role of PHD2 in the regulation of HIF-1 $\alpha$ levels, it was hypothesized in the present study that the PHD2 signaling pathway has a role in ovarian angiogenesis and that overexpression of PHD2 attenuates the expression of VEGF induced by hypoxia in LCs. The present study examined the effect of hypoxia on the expression of HIF-1 $\alpha$ and determined the role of PHD2, the primary isoform of PHDs, in hypoxia-induced activation of HIF-1 $\alpha$ by transfection of PHD2-expressing vectors into LCs. The effect on VEGF mRNA expression was also examined. The results indicated that PHD2 is a mediator of cellular HIF-1 $\alpha$ and its target gene VEGF in LCs, which may be an important regulatory mechanism of VEGF-dependent angiogenesis during mammalian CL development.

\section{Materials and methods}

Animals.25-day-old Female Sprague-Dawley (SD) rats (Fuzhou Animal Center, Fuzhou, China) were used in the present study. All animals were maintained under a 12-h light/dark cycle with food and water available ad libitum. The study was conducted in accordance with guidelines of the Institutional Animal Care and Use Committee and was approved by the Ethics Committee on Animal Experimentation of Fujian Normal University. All efforts were made to minimize animal discomfort and to reduce the number of animals used.

Isolation and culture of rat LCs. Rat LCs were isolated and cultured according to previously described procedures (27-29). Briefly, the rats received a subcutaneous injection of equine chorionic gonadotropin [eCG; Sigma-Aldrich, St. Louis, MO, USA; 50 international units (IU)] and an ovulatory dose (25 IU) of human chorionic gonadotropin (hCG; Sigma-Aldrich) $64 \mathrm{~h}$ later. Ovaries was obtained at day 5 after hCG injection and minced with a razor blade. Tissue was digested in medium 199 (Gibco-BRL, Invitrogen Life Technologies, Carlsbad, CA, USA) containing $1 \%$ fetal calf serum (FCS; Gibco-BRL) and 2,000 IU collagenase (Gibco-BRL) plus 3,000 IU of DNase (SigmaAldrich) per gram of tissue for $1 \mathrm{~h}$ at $37^{\circ} \mathrm{C}$ under $95 \%$ air with $5 \% \mathrm{CO}_{2}$. The contents of the flask were filtered through nylon mesh (BD Biosciences, Franklin Lakes, NJ, USA) and centrifuged (100 xg, $5 \mathrm{~min}$ ); the supernatant fraction was discarded and the pellet was washed three times with fresh medium. The final cell concentration was $10^{6}$ cells per $\mathrm{ml}$ and cells were incubated in six-well culture plates. Cell numbers were determined with a hemocytometer and cell viability was $>90 \%$ as assessed by Trypan blue (Sigma-Aldrich) staining exclusion.

Transfection of plasmids expressing rat PHD2 into the cells. Plasmids encoding rat full-length PHD2 cDNA were a generous gift from Dr Ningjun Li (Department of Pharmacology \&
Toxicology, School of Medicine, Virginia Commonwealth University, Richmond, VA, USA). The expression and function of rat PHD2 protein by the plasmids has been validated by previous studies (25,30-32). Plasmid transfections were performed using lipids (DOTAP/DOPE; Avanti Polar Lipids, Inc., Alabaster, AL, USA) according to the manufacturer's instructions. In brief, $5 \mu \mathrm{g}$ DNA was mixed with a lipid solution at a DNA/lipid ratio of 1:10 (w/w) in serum-free culture medium ( $5 \mathrm{ml}$ for a $10-\mathrm{cm}$ dish). Cells were incubated with this transfection medium for $5 \mathrm{~h}$ and switched to normal medium for another $16 \mathrm{~h}$. The cells were then ready for the subsequent experiments.

Cell hypoxia. Cell culture under hypoxia with $3 \% \mathrm{O}_{2}$ was performed as described previously $(33,34)$. Briefly, LCs were plated in six-well plates $24 \mathrm{~h}$ prior to the experiments to reach sub-confluence. To decrease $\mathrm{O}_{2}$ pressure in the culture medium, the plates and dishes were transferred to a sealed, humidified modular chamber, the atmospheric air was evacuated by a vacuum pump, and the chamber was re-filled with a non-standard gas mixture containing $3 \% \mathrm{O}_{2}$ and $5 \% \mathrm{CO}_{2}$ in an $\mathrm{N}_{2}$ base. After repeating this evacuation and inflow five times, the cells were cultured for $6 \mathrm{~h}$. After hypoxia, the culture medium was rapidly replaced by TRIzol solution (Invitrogen Life Technologies), and total RNA was extracted for determination of HIF-1 $\alpha$ and VEGF mRNA. For HIF-1 $\alpha$ protein determination, the cultured cells were scraped immediately and placed in ice-cold homogenization buffer [25 mM Tris-HCl, $300 \mathrm{mM}$ sucrose, $2 \mathrm{mM}$ EDTA, protease inhibitor cocktail (Roche Diagnostics, Basel, Switzerland), $\mathrm{pH} 7.4]$, frozen in liquid nitrogen and then stored at $-80^{\circ} \mathrm{C}$ for western blot analysis.

RNA extraction and quantitative reverse transcription polymerase chain reaction (RT-PCR) analysis of PHD1, 2 and 3, HIF- $1 \alpha$ and VEGF. Total RNA was extracted using TRIzol solution and then reverse-transcribed uding a cDNA Synthesis kit (Bio-Rad Laboratories, Inc., Hercules, CA, USA). The RT products were amplified using SYBR green (Bio-Rad Laboratories, Inc.) and the following primers: PHD1 forward, 5'-GCTGCTGCGTTGGTTAC-3' and reverse; 5'-GCCTCCTGGTTCTCTTG-3' (GenBank accession no.: NM001004083); PHD2 forward, 5'-CTGGGACGCCAA GGTGA-3' and reverse, 5'-CAATGTCAGCAAACTGG-3' (GenBank accession no.: NM178334); PHD3 forward, 5'-GTT CAGCCCTCCTATGC-3' and reverse, 5'-ACCACCGTCAGT CTTTA-3' (GenBank accession no.: NM019371); HIF-1 $\alpha$ forward, 5'-CTGGCACGGGGATGATACAGC-3' and reverse, 5'-TCTCATCCATTGACTGCCCCAG-3' (GenBank accession no.: AF057308) and VEGF forward, 5'-ACGAAGCGC AAGAAATCCC-3' and reverse, 5'-TTAACTCAAGCTGCC TCGCC-3' (GenBank accession no.: M32167) with an iCycler iQ Real Time PCR Detection System (Bio-Rad Laboratories, Inc.). The levels of 18 rRNA [forward, 5'-CGCCGCTAGAGG TGAAATTC-3' and reverse, 5'-TCTTGGCAAATGCTT TCGC-3' (GenBank accession no.: M11188)] were used as an endogenous control. The $25 \mu \mathrm{l}$ PCR reaction mix included 12.5 $\mu \mathrm{l} \mathrm{SYBR}$ Green PCR Master Mix, $2.5 \mu 1$ 10X primers, $1 \mu \mathrm{l}$ cDNA template and $9 \mu \mathrm{l}$ RNase-free water. The PCR conditions were as follows: $50^{\circ} \mathrm{C}$ for $2 \mathrm{~min}, 95^{\circ} \mathrm{C}$ for $15 \mathrm{~min}$, followed by 40 cycles at $94^{\circ} \mathrm{C}$ for $15 \mathrm{sec}, 60^{\circ} \mathrm{C}$ for $30 \mathrm{sec}$ and $72^{\circ} \mathrm{C}$ for $30 \mathrm{sec}$. Relative gene expression was calculated in 


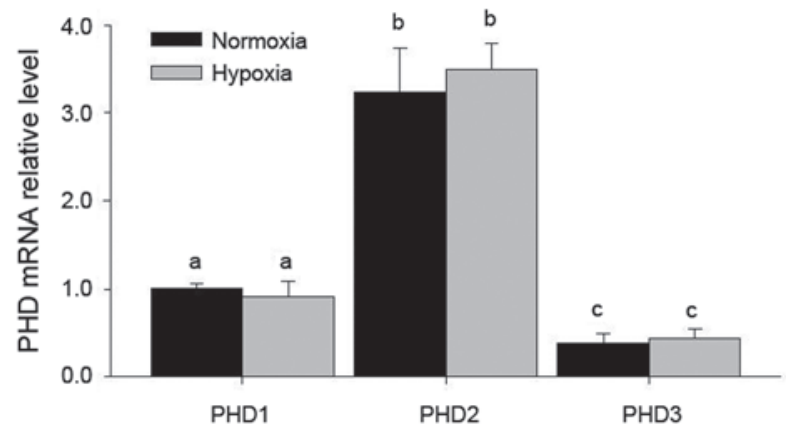

Figure 1. Effects of hypoxia on the mRNA expression of PHD2 in luteal cells. Relative mRNA levels of PHDs were assessed by reverse transcription polymerase chain reaction analysis. Values are expressed as the mean \pm standard error $(n=6)$. Different letters denote statistically significant differences between values $(\mathrm{P}<0.05)$. PHD, hypoxia-inducible factor prolyl-hydroxylase.

accordance with the $\Delta \Delta \mathrm{Ct}$ method, with relative mRNA levels calculated as $2^{-\Delta \Delta \mathrm{Ct}}$.

Preparation of nuclear extracts and cytosolic protein, and western blot analysis of protein levels of HIF-1 $\alpha$ and PHD. Nuclearprotein was prepared as previously described(12,25,32). Cytosolic protein and nuclear protein were collected separately (Beyotime Institute of Biotechnology, Haimen, China). The cytosolic protein was used for western blot analysis of PHD2, while the nuclear fraction was used for western blot analyses of HIF-1 $\alpha$. Briefly, protein concentration was determined using a Bio-Rad assay (Bio-Rad Laboratories, Inc.) with bovine serum albumin standards. The protein samples $(30 \mu \mathrm{g})$ were separated by $8 \%$ SDS-PAGE, and were electrophoretically transferred to a polyvinylidene fluoride membrane (Pall Corporation, Pensacola, FL, USA). The membrane was washed with phosphate-buffered saline with 0.2\% Tween-20 (PBST; Sigma-Aldrich), blocked with 5\% nonfat dried milk in PBST and probed with the following primary antibodies (Novus Biologicals, Littleton, CO, USA): Mouse monoclonal anti-HIF-1 $\alpha$ (1:300; cat. no. NB100-105), rabbit polyclonal anti-PHD2 (1:300; cat. no. NB100-137), and rabbit polyclonal anti- $\beta$-actin (cat. no. NB600-503H) overnight at $4^{\circ} \mathrm{C}$. After washing, the membranes were then incubated with horseradish peroxidase-conjugated goat anti-mouse (1:5,000; cat. no. NB7570) or goat anti-rabbit $(1: 5,000$, cat. no. NBP2-30348H) immunoglobulin G secondary antibodies (Novus Biologicals) for $1 \mathrm{~h}$ at room temperature. $\beta$-actin was used as a loading control (1:5,000, cat. no. NB600-501H). To detect the immunoblotting signal $2 \mathrm{ml}$ enhanced chemiluminescence detection solution (Thermo Scientific, Rockford, IL, USA) was used, and the membrane was exposed to Kodak OMAT film (Eastman Kodak, Rochester, NY, USA). The blots were quantified using ImageJ software (National Institutes of Health, Bethesda, MD, USA)

Determination of HIF prolyl hydroxylase activity. HIF-1 $\alpha$ peptide-specific conversion of 2-oxoglutarate into succinate provides a hydroxyl group for HIF-1 $\alpha$ to be prolyl hydroxylated. This reaction has been widely used for the determination of PHD activity by measuring HIF- $1 \alpha$-dependent conversion rate of 2-oxoglutarate into succinate $(25,35,36)$.

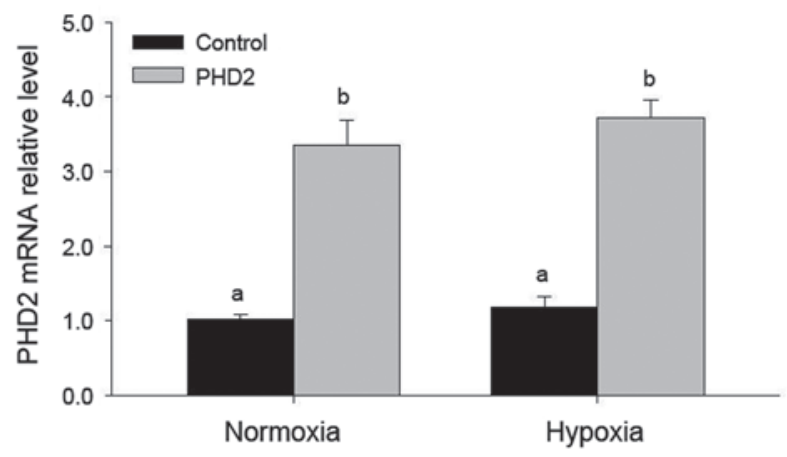

Figure 2. Effects of hypoxia and PHD2 plasmid on PHD2 mRNA levels in luteal cells. Relative mRNA levels of PHD2 were assessed by reverse transcription polymerase chain reaction analysis. Values are expressed as the mean \pm standard error $(n=6)$. Different letters denote statistically significant differences between values $(\mathrm{P}<0.05)$. PHD, hypoxia-inducible factor prolyl-hydroxylase.

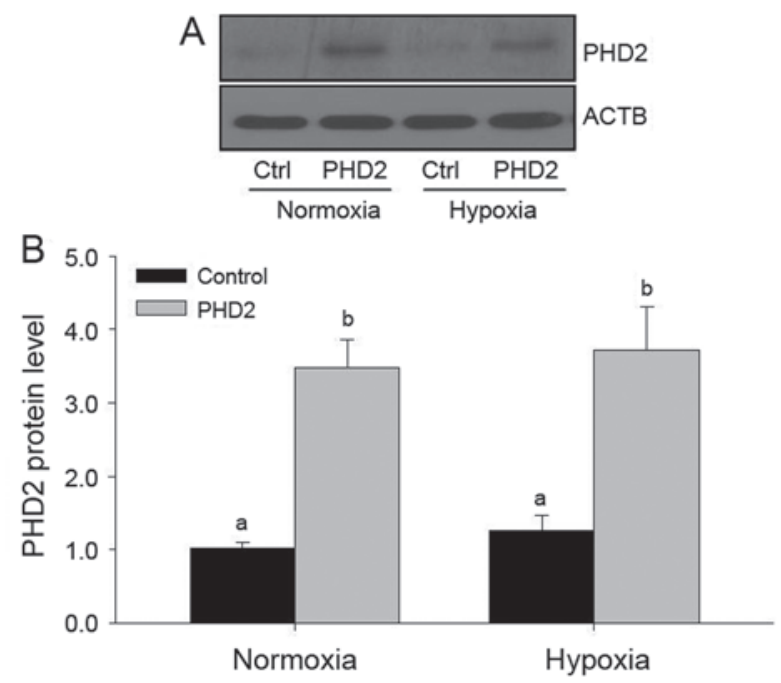

Figure 3. Effects of hypoxia and PHD2 plasmid on PHD2 protein levels in luteal cells. (A) Representative western blot depicting the protein levels of PHD2. (B) Quantified intensities of PHD2 blots normalized to ACTB Values are expressed as the mean \pm standard error $(n=6)$. Different letters denote statistically significant differences between values $(\mathrm{P}<0.05)$. PHD, hypoxia-inducible factor prolyl-hydroxylase; ACTB, $\beta$-actin

Statistics. Values are expressed as the mean \pm standard error. The significance of differences in mean values within and between multiple groups was evaluated using analysis of variance followed by a Duncan's multiple range test. Statistical analysis was conducted using Sigmastat 3.02 (Sigma-Aldrich). $\mathrm{P}<0.05$ was considered to indicate a statistically significant difference.

\section{Results}

PHD2 is the most abundantly expressed PHD in LCs, and is not affected by hypoxia. RT-qPCR indicated that all of three PHDs were present, among which PHD2 was most abundantly expressed in LCs (Fig. 1), while no significant changes of these mRNA levels were found after hypoxia treatment (Fig. 1).

Efficient PHD2 transfection in LCs is not affected by hypoxia. PHD2 mRNA levels increased significantly after PHD2 trans- 


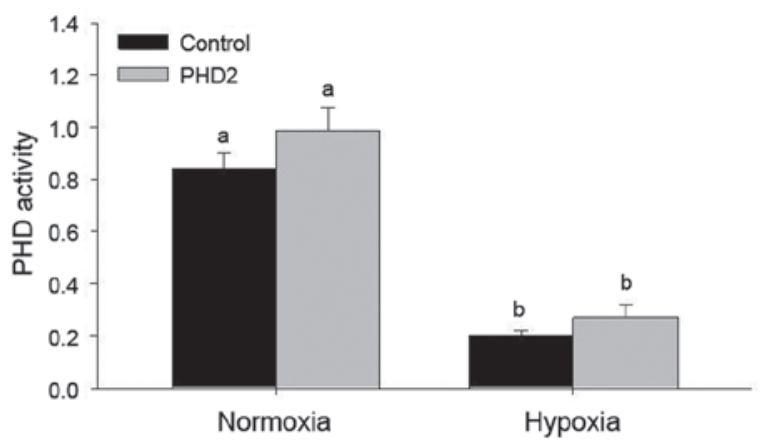

Figure 4. Effects of hypoxia and PHD2 plasmid on PHD activity in luteal cells. PHD activity in each group by $\left[{ }^{14} \mathrm{C}\right]-2$-oxoglutarate conversion rate. Values are expressed as the mean \pm standard error $(n=6)$. Different letters denote statistically significant differences between values $(\mathrm{P}<0.05)$. PHD, hypoxia-inducible factor prolyl-hydroxylase.

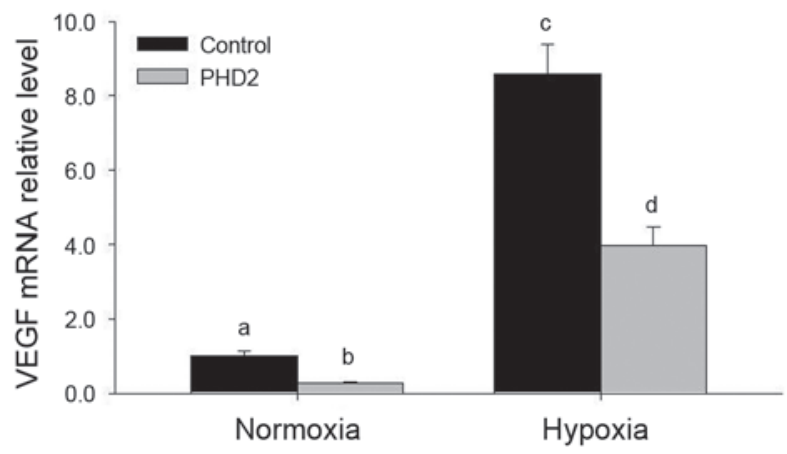

Figure 5. Effects of hypoxia and PHD2 plasmid on VEGF mRNA levels in luteal cells. Relative mRNA levels of VEGF were assessed by reverse transcription polymerase chain reaction analysis. Values are expressed as the mean \pm standard error $(n=6)$. Different letters denote statistically significant differences between values $(\mathrm{P}<0.05)$. PHD, hypoxia-inducible factor prolyl-hydroxylase; VEGF, vascular endothelial growth factor.

fection, even following hypoxia treatment (Fig. 2). However hypoxia was found to have no marked effect on PHD2 mRNA expression (Fig. 2), indicating the high transfection efficiency and the high expression levels of PHD2 plasmid.

Furthermore, PHD2 protein levels were detected by western blot analysis (Fig. 3). The results indicated that, similar to mRNA levels, PHD2 protein levels were enhanced following transfection, but that hypoxia had no effects on PHD2 protein levels (Fig. 3).

Effects of hypoxia and PHD2 transfection on PHD2 protein levels and PHD2 activity in LCs. To further confirm stable transfection of PHD2 into LCs, PHD2 biological activity was tested using the 2-oxoglutarate conversion assay (Fig. 4). In the PHD2-transfected groups, 2-oxoglutarate conversion was enhanced, however, not to a statistically significant extent. Of note, a significant decrease of PHD activity was found in LCs under hypoxic conditions, even following transfection with PHD2 plasmids (Fig. 4).

Hypoxia increases and PHD2 transfection decreases VEGF mRNA levels in LCs, while HIF-1a mRNA is unaffected. In the present study, hypoxia significantly increased VEGF mRNA expression in LCs (Fig. 5). To better understand the

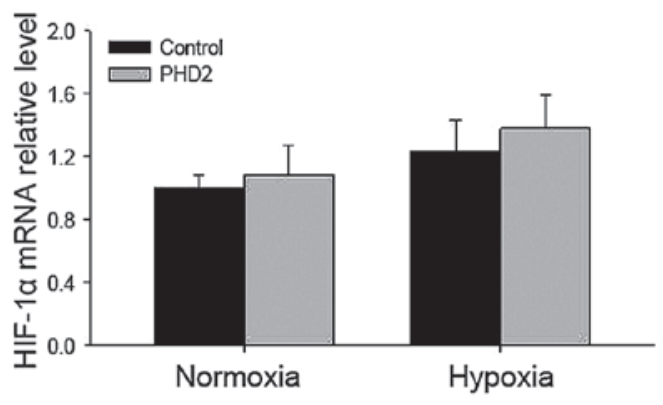

Figure 6. Effects of hypoxia and PHD2 plasmid on HIF-1alpha mRNA levels in luteal cells. The relative mRNA levels of HIF-1alpha were assessed by reverse transcription polymerase chain reaction analysis. Values are expressed as the mean \pm standard error $(n=6)$. No statistically significant differences between values were present. HIF, hypoxia-inducible factor; PHD, HIF prolyl-hydroxylase.

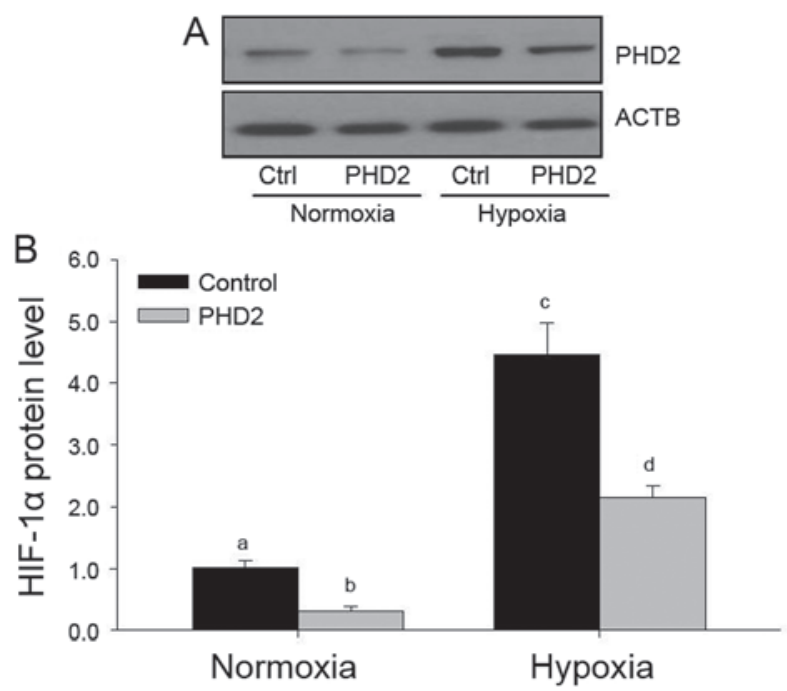

Figure 7. Effects of human chorionic gonadotropin and PHD2 plasmid on HIF-1alpha protein levels in luteal cells. (A) Representative western blot depicting the protein levels of HIF-1alpha. (B) Quantified intensities of HIF-1alpha normalized to ACTB. Values are expressed as the mean \pm standard error $(n=6)$. Different letters denote statistically significant differences between values $(\mathrm{P}<0.05)$. HIF, hypoxia-inducible factor; PHD, HIF prolyl-hydroxylase; ACTB, $\beta$-actin.

role of PHD2 in LCs, the mRNA levels of VEGF and HIF-1 $\alpha$ in LCs transfected with PHD2 plasmid were also examined (Figs. 5 and 6). Of note, a marked decrease in VEGF levels was observed in PHD2-transfected LCs (Fig. 5), while HIF-1 $\alpha$ mRNA levels were not significantly altered in LCs following hypoxia treatment (Fig. 6).

Effects of hypoxia and PHD2 transfection on HIF-1 $\alpha$ protein levels in LCs. It has been demonstrated that PHDs are major enzymes to promote the degradation of HIF-1 $\alpha$ (21-24); therefore, the present study examined the HIF-1 $\alpha$ protein levels in each group (Fig. 7). Hypoxia inhibited HIF-1 $\alpha$ protein expression under normoxic and hypoxic conditions (Fig. 7), and a significant decrease of HIF-1 $\alpha$ protein was found in PHD2-transfected LCs, which was consistent with the results of previous studies by our group $(25,32)$, indicating that PHD2 may regulate VEGF expression via the HIF-1 $\alpha$ pathway in LCs during CL development. 


\section{Discussion}

The results of the present study clearly demonstrated that hypoxia induced VEGF through inhibiting HIF-1 $\alpha$ signaling in LCs, which was attenuated by overexpression of PHD2, suggesting that PHD2-mediated VEGF expression via the HIF-1 $\alpha$ pathway may be an important mechanism of VEGF-dependent angiogenesis during mammalian CL development.

The CL is a temporary endocrine structure in mammals, which has an important role in the female reproductive cycle and is formed temporarily from a ruptured and ovulated follicle with rapid angiogenesis $(5,6,11,37,38)$. VEGF is thought to have a paramount role in the regulation of normal and abnormal angiogenesis in the ovary $(2-4,6,9,11,39,40)$, particularly in the newly formed CL. Numerous studies have shown that reproductive hormones such as hCG also take part in the primary regulation of VEGF expression in the ovary. For example, VEGF mRNA expression in human luteinized granulosa cells has been shown to be dose- and time-dependently enhanced by hCG in vitro $(9,10)$. Chronic or acute exposure to hCG directly stimulates VEGF production and secretion by monkey (1) and human luteinized granulosa cells $(5,9,10,40)$. Furthermore, the administration of a gonadotropin-releasing hormone antagonist decreased VEGF mRNA expression in the CL of monkeys (41). In addition, luteal vascularization and the development of ovarian hyperstimulation syndrome (OHSS) are absolutely dependent on LH/hCG stimulation $(9,10)$. Furthermore, in a fully formed, highly vascular CL hCG also up-regulates VEGF expression (5). However, a previous study by our group has already provided direct evidence that VEGF is transcriptionally activated by a HIF-1-mediated mechanism in LCs under hypoxia (12), which is caused by ovulation of the ruptured follicle with bleeding and an immature vasculature $(2,38)$. Therefore, the present study examined the induced effect of hypoxia and PHD2 overexpression on VEGF mRNA expression in LCs. Of note, VEGF expression was induced by hypoxia in LCs and hypoxia-stimulated HIF-1 $\alpha$ protein expression was highly correlated with VEGF expression, indicating hypoxia stimulated VEGF expression via the HIF-1 $\alpha$ signaling pathway.

Numerous studies have indicated that HIF-1 $\alpha$ regulates the expression of numerous genes whose protein products have critical roles in developmental and physiological processes, including angiogenesis, erythropoiesis, glycolysis, iron transport and cell proliferation/survival $(5,38,42-45)$. Because HIF- $1 \alpha$ activates the transcription of VEGF, which is required for angiogenesis, it is possible that hypoxia may mediate angiogenesis via the HIF-1 $\alpha /$ VEGF pathway. In addition to a detailed exploration of the downstream mechanism of HIF-1 $\alpha(12,46-48)$, recent studies have clarified the upstream process modulated by PHDs (49), which regulates HIF-1 $\alpha$ degradation by the ubiquitin-proteasome pathway. In particular, PHD2 has been drawing considerable attention because PHD2 is considered to be the key oxygen sensor of all identified PHD enzymes $(25,26)$, as knockdown of PHD2 resulted in elevated HIF protein levels (49), and several recent studies have also highlighted the importance of PHD2 in tumourigenesis (26). The present study reported that hypoxia induced the activation of HIF-1 $\alpha$ and overexpression of PHD2 blocked this activation of HIF-1 $\alpha$ and its target gene VEGF following hypoxia treatment. These results indicated that PHD2 is involved in HIF-1 $\alpha$-mediated gene activation in LCs under hypoxia, which may present a novel mechanism of VEGF-dependent angiogenesis during mammalian CL development.

In conclusion, the present study clearly demonstrated that hypoxia induces HIF-1 $\alpha$ and VEGF expression in LCs. To the best of our knowledge, the present study was also the first to provide direct evidence indicating that PHDs are expressed in rat LCs and that hypoxia-induced VEGF expression can be blocked by overexpression of PHD2 in LCs. This PHD2-mediated VEGF expression may be one of the important mechanisms of VEGF-dependent angiogenesis during CL formation in the mammalian ovary. Furthermore, this PHD2 antagonism presents an opportunity for the development of novel treatments for fertility control and for certain types of ovarian dysfunction $(26,44,45)$, particularly conditions characterized by pathological angiogenesis and excessive vascular permeability, including polycystic ovarian syndrome (PCOS), OHSS and ovarian neoplasia.

\section{Acknowledgements}

This study was supported by the National Natural Science Foundation of China (nos. 31101032 and 31271255), the Program for New Century Excellent Talents in University of the Ministry of Education of China (no. NCET-120614), the Doctoral Foundation of the Ministry of Education of China (no. 20113503120002) and Fujian Provincial Science and Technology Projects of the Department of Education (no. JB14041). The authors particularly thank Dr Ningjun Li from Department of Pharmacology \& Toxicology, School of Medicine, Virginia Commonwealth University in the USA for kindly providing the PHD and control plasmids.

\section{References}

1. Christenson LK and Stouffer RL: Follicle-stimulating hormone and luteinizing hormone/chorionic gonadotropin stimulation of vascular endothelial growth factor production by macaque granulosa cells from pre- and periovulatory follicles. J Clin Endocrinol Metab 82: 2135-2142, 1997.

2. Kaczmarek MM, Schams D and Ziecik AJ: Role of vascular endothelial growth factor in ovarian physiology-an overview. Reprod Biol 5: 111-136, 2005.

3. Shimizu T and Miyamoto A: Progesterone induces the expression of vascular endothelial growth factor (VEGF) 120 and Flk-1, its receptor, in bovine granulosa cells. Anim Reprod Sci 102: 228-237, 2007.

4. Shimizu T, Jayawardana BC, Tetsuka M and Miyamoto A: Differential effect of follicle-stimulating hormone and estradiol on expressions of vascular endothelial growth factor (VEGF) 120 , VEGF164 and their receptors in bovine granulosa cells. J Reprod Dev 53: 105-112, 2007.

5. Wulff C, Dickson SE, Duncan WC and Fraser HM: Angiogenesis in the human corpus luteum: simulated early pregnancy by HCG treatment is associated with both angiogenesis and vessel stabilization. Hum Reprod 16: 2515-2524, 2001.

6. Fraser HM, Bell J, Wilson H, Taylor PD, Morgan K, et al: Localization and quantification of cyclic changes in the expression of endocrine gland vascular endothelial growth factor in the human corpus luteum. J Clin Endocrinol Metab 90: 427-434, 2005.

7. Fraser HM, Wilson H, Wulff C, Rudge JS and Wiegand SJ: Administration of vascular endothelial growth factor Trap during the 'post-angiogenic' period of the luteal phase causes rapid functional luteolysis and selective endothelial cell death in the marmoset. Reproduction 132: 589-600, 2006. 
8. Duncan WC, van den Driesche S and Fraser HM: Inhibition of vascular endothelial growth factor in the primate ovary up-regulates hypoxia-inducible factor-1alpha in the follicle and corpus luteum. Endocrinology 149: 3313-3320, 2008.

9. Neulen J, Yan Z, Raczek S, Weindel K, Keck C, et al: Human chorionic gonadotropin-dependent expression of vascular endothelial growth factor/vascular permeability factor in human granulosa cells: importance in ovarian hyperstimulation syndrome. J Clin Endocrinol Metab 80: 1967-1971, 1995.

10. Nastri CO, Ferriani RA, Rocha IA and Martins WP: Ovarian hyperstimulation syndrome: pathophysiology and prevention. J Assist Reprod Genet 27: 121-128, 2010.

11. Zhang Z, Neiva KG, Lingen MW, Ellis LM and Nör JE: VEGF-dependent tumor angiogenesis requires inverse and reciprocal regulation of VEGFR1 and VEGFR2. Cell Death Differ 17: 499-512, 2010.

12. Zhang Z, Yin D and Wang Z: Contribution of hypoxia-inducible factor- $1 \alpha$ to transcriptional regulation of vascular endothelial growth factor in bovine developing luteal cells. Anim Sci J 82 244-250, 2010

13. Wang GL and Semenza GL: Characterization of hypoxia-inducible factor 1 and regulation of DNA binding activity by hypoxia. J Biol Chem 268: 21513-21518, 1993.

14. Wang GL and Semenza GL: Desferrioxamine induces erythropoietin gene expression and hypoxia-inducible factor 1 DNA-binding activity: implications for models of hypoxia signal transduction. Blood 82: 3610-3615, 1993.

15. Wang GL and Semenza GL: Purification and characterization of hypoxia-inducible factor 1. J Biol Chem 270: 1230-1237, 1995.

16. Wang GL, Jiang BH, Rue EA and Semenza GL: Hypoxia-inducible factor 1 is a basic-helix-loop-helix-PAS heterodimer regulated by cellular $\mathrm{O}_{2}$ tension. Proc Natl Acad Sci USA 92: 5510-5514, 1995

17. Wenger RH, Rolfs A, Marti HH, Guénet JL and Gassmann M Nucleotide sequence, chromosomal assignment and mRNA expression of mouse hypoxia-inducible factor-1 alpha. Biochem Biophys Res Commun 223: 54-59, 1996.

18. Kazi AA, Jones JM and Koos RD: Chromatin immunoprecipitation analysis of gene expression in the rat uterus in vivo: estrogen-induced recruitment of both estrogen receptor alpha and hypoxia-inducible factor 1 to the vascular endothelial growth factor promoter. Mol Endocrinol 19: 2006-2019, 2005

19. Kazi AA and Koos RD: Estrogen-induced activation of hypoxia-inducible factor-1alpha, vascular endothelial growth factor expression and edema in the uterus are mediated by the phosphatidylinositol 3-kinase/Akt pathway. Endocrinology 148: 2363-2374, 2007.

20. Molitoris KH,Kazi AA and Koos RD: Inhibition of oxygen-induced hypoxia-inducible factor-1alpha degradation unmasks estradio induction of vascular endothelial growth factor expression in ECC-1 cancer cells in vitro. Endocrinology 150: 5405-5414, 2009.

21. Bruick RK and McKnight SL: A conserved family of prolyl-4-hydroxylases that modify HIF. Science 294: 1337-1340, 2001.

22. Ivan M, Kondo K, Yang H, Kim W, Valiando J, et al: HIFalpha targeted for VHL-mediated destruction by proline hydroxylation: implications for $\mathrm{O}_{2}$ sensing. Science 292: 464-468, 2001.

23. Jaakkola P, Mole DR, Tian YM, Wilson MI, Gielbert J, et al: Targeting of HIF-alpha to the von Hippel-Lindau ubiquitylation complex by $\mathrm{O}_{2}$-regulated prolyl hydroxylation. Science 292 468-472, 2001

24. Epstein AC, Gleadle JM, McNeill LA, Hewitson KS O'Rourke J, et al: C. elegans EGL-9 and mammalian homologs define a family of dioxygenases that regulate HIF by prolyl hydroxylation. Cell 107: 43-54, 2001.

25. Wang Z,Zhu Q, Xia M,Li PL, Hinton SJ, et al: Hypoxia-inducible factor prolyl-hydroxylase 2 senses high-salt intake to increase hypoxia inducible factor 1alpha levels in the renal medulla. Hypertension 55: 1129-1136, 2010.

26. Chan DA and Giaccia AJ: PHD2 in tumour angiogenesis. Br J Cancer 103: 1-5, 2010

27. Thomas JP, Dorflinger LJ and Behrman HR: Mechanism of the rapid antigonadotropic action of prostaglandins in cultured lutea cells. Proc Natl Acad Sci USA 75: 1344-1348, 1978.

28. Conti M, Harwood JP, Dufau ML and Catt KJ: Effect of gonadotropin-induced receptor regulation on biological responses of isolated rat luteal cells. J Biol Chem 252: 8869-8874, 1977.

29. Pepperell JR, Porterfield DM, Keefe DL, Behrman HR and Smith PJ: Control of ascorbic acid efflux in rat luteal cells: role of intracellular calcium and oxygen radicals. Am J Physiol Cell Physiol 285: C642-C651, 2003.
30. Huang J, Zhao Q, Mooney SM and Lee FS: Sequence determinants in hypoxia-inducible factor-1alpha for hydroxylation by the prolyl hydroxylases PHD1, PHD2 and PHD3. J Biol Chem 277: 39792-39800, 2002

31. Percy MJ, Zhao Q, Flores A, Harrison C, Lappin TR, et al A family with erythrocytosis establishes a role for prolyl hydroxylase domain protein 2 in oxygen homeostasis. Proc Natl Acad Sci USA 103: 654-659, 2006

32. Li N, Yi F, Sundy CM, Chen L, Hilliker ML, et al: Expression and actions of HIF prolyl-4-hydroxylase in the rat kidneys. Am J Physiol Renal Physiol 292: F207-F216, 2007.

33. Nishimura R, Sakumoto R, Tatsukawa Y, Acosta TJ and Okuda K: Oxygen concentration is an important factor for modulating progesterone synthesis in bovine corpus luteum. Endocrinology 147: 4273-4280, 2006.

34. Okuda K, Miyamoto A, Sauerwein H, Schweigert FJ and Schams D: Evidence for oxytocin receptors in cultured bovine luteal cells. Biol Reprod 46: 1001-1006, 1992.

35. Richard-Fiardo P, Payen E, Chèvre R, Zuber J,Letrou-Bonneval E, et al: Therapy of anemia in kidney failure, using plasmid encoding erythropoietin. Hum Gene Ther 19: 331-342, 2008.

36. Yi F, Xia M, Li N, Zhang C, Tang L and Li PL: Contribution of guanine nucleotide exchange factor Vav2 to hyperhomocysteinemic glomerulosclerosis in rats. Hypertension 53: 90-96, 2009.

37. Young FM, Rodger FE, Illingworth PJ and Fraser HM: Cell proliferation and vascular morphology in the marmoset corpus luteum. Hum Reprod 15: 557-566, 2000.

38. Nishimura R and Okuda K: Hypoxia is important for establishing vascularization during corpus luteum formation in cattle. J Reprod Dev 56: 110-116, 2010.

39. van den Driesche S, Myers M, Gay E, Thong KJ and Duncan WC: HCG up-regulates hypoxia inducible factor-1 alpha in luteinized granulosa cells: implications for the hormonal regulation of vascular endothelial growth factor $\mathrm{A}$ in the human corpus luteum. Mol Hum Reprod 14: 455-464, 2008.

40. Lee A, Christenson LK, Patton PE, Burry KA and Stouffer RL: Vascular endothelial growth factor production by human luteinized granulosa cells in vitro. Hum Reprod 12: 2756-2761, 1997.

41. Ravindranath N, Little-Ihrig L, Phillips HS, Ferrara N and Zeleznik AJ: Vascular endothelial growth factor messenger ribonucleic acid expression in the primate ovary. Endocrinology 131: 254-260, 1992

42. Zhong H, Chiles K, Feldser D, Laughner E, Hanrahan C, et al: Modulation of hypoxia-inducible factor 1alpha expression by the epidermal growth factor/phosphatidylinositol 3-kinase/PTEN/AKT/FRAP pathway in human prostate cancer cells: implications for tumor angiogenesis and therapeutics. Cancer Res 60: 1541-1545, 2000.

43. Yaba A, Bianchi V, Borini A and Johnson J: A putative mitotic checkpoint dependent on mTOR function controls cell proliferation and survival in ovarian granulosa cells. Reprod Sci 15 $128-138,2008$

44. Miyazawa M, Yasuda M, Fujita M, Kajiwara H, Hirabayashi K, et al: Therapeutic strategy targeting the mTOR-HIF-1alpha-VEGF pathway in ovarian clear cell adenocarcinoma. Pathol Int 59: 19-27, 2009.

45. Miyazawa M, Yasuda M, Fujita M, Hirabayashi K, Hirasawa T, et al: Granulosa cell tumor with activated mTOR-HIF-1alpha-VEGF pathway. J Obstet Gynaecol Res 36: 448-453, 2010

46. Zhang Z, Yu D, Yin D and Wang Z: Activation of PI3K/mTOR signaling pathway contrbutes to induction of vascular endothelial growth factor by hCG in bovine developing luteal cells. Anim Reprod Sci 125: 42-48, 2011.

47. Zhang J, Zhang Z, Wu Y, Chen L, Luo Q, Chen J, Huang X, Cheng Y and Wang Z: Regulatory effect of hypoxia-inducible factor- $1 \alpha$ on hCG-stimulated endothelin-2 expression in granulosa cells from the PMSG-treated rat ovary. J Reprod Dev 58: 678-684, 2012.

48. Li N, Chen L, Yi F, Xia M and Li PL: Salt-sensitive hypertension induced by decoy of transcription factor hypoxia-inducible factor-1alpha in the renal medulla. Circ Res 102: 1101-1108, 2008.

49. Zhu Q, Hu J, Han WQ, Zhang F,Li PL, Wang Z and Li N: Silencing of HIF prolyl-hydroxylase 2 gene in the renal medulla attenuates salt-sensitive hypertension in Dahl S rats. Am J Hypertens 27: 107-113, 2014. 